APROVEITAMENTO DE RESÍDUOS DA FABRICAÇÃO DE CACHAÇA PARA PRODUÇÃO DE ETANOL

\title{
APROVEITAMENTO DE RESÍDUOS DA FABRICAÇÃO DE CACHAÇA PARA PRODUÇÃO DE ETANOL
}

Wesley Antunes Meireles M.Sc Professor de ensino básico, técnico e tecnológico do Instituto Federal do Norte de Minas Gerais - Campus Salinas,wesley.meireles@oi.com.br

Valdenir Pereira de Oliveira - Graduando em Tecnologia em Produção de Cachaça - IFNMG

Lília Cristina Ferreira - Graduanda em Tecnologia em Produção de Cachaça - IFNMG

Klícia M. Marinho Soares - Graduanda em Tecnologia em Produção de Cachaça - IFNMG

Lenir de Abreu D.Sc Professor de ensino básico, técnico e tecnológico do Instituto Federal do Norte de Minas Gerais - Campus Januária.

\section{RESUMO}

O presente trabalho objetiva a produção de etanol a partir de subprodutos originados da produção de cachaça como potencial fonte de renda para produtores rurais visando diminuição de impactos ambientais e viabilidade econômico-financeira. O trabalho foi realizado na Fazenda Vargem Grande, no município de Salinas-MG, durante a safra 2008/2009, em que foram realizadas pesquisas na produção de etanol, visando uma viabilidade técnica, ambiental e econômica. Para isso, foi analisado volume de produção de etanol, grau alcoólico, avaliação dos custos e receitas do investimento. Os resultados demonstraram ser viáveis com produção de 8.000 litros de etanol, uma lucratividade de $56,45 \%$, rentabilidade de $28,21 \%$ e prazo de retorno do investimento de 3,54 anos.

Palavras-chave: etanol, cachaça, subprodutos, viabilidade.

\section{ABSTRACT}

This present work object ethanol production of by-product originated of spirit factory like pontential source of money to farmer aim dicreasing of enviroment impacts and economic viability. The work were doing of Vargem Grande Farm, in Salinas-MG city, during 2008/2009 ages, wich has doing research in ethanol production, aim technique viability, enviromental and economic. To this, were analysed bulk of ethanol production, alcoolic grade, evaluation of costs and receipt of investment. Build on demonstrated viability wich production of 8,000 liter ethanol, lucrativeness of $56.45 \%$, profitability of $28.21 \%$ and period pay-back of 3.54 ages.

Keywords: ethanol, spirit, by-product, viability.

\section{INTRODUÇÃO}

A cachaça pertence à nobre família das aguardentes, da eau-de-vie ou aquavit (CHRISTOPH \& CHRISTOPH, 2007). Trata-se de um destilado feito à base de cana-de-açúcar, leveduras e água (CARDOSO, 2006).

Com o aumento da produtividade nas agroindústrias, há uma crescente busca da utilização dos resíduos gerados, pois o acúmulo destes gera a deterioração do meio ambiente e perda de recursos, considerando-se que uma tonelada de cana-de-açúcar gera 120 litros de cachaça e 780 litros de vinhoto e $240 \mathrm{~kg}$ de bagaço (SEBRAE, 2001b). Entretanto, outros resíduos da fabricação de cachaça ainda são pouco estudados.

Durante o processo de extração do caldo da cana-de-açúcar, mesmo com todos os cuidados durante a colheita, transporte e estocagem, contém várias impurezas grosseiras, principalmente bagacilho e terra, os quais devem ser retiradas (BOZA \& HORII, 1998). Quanto mais limpo for o caldo 
destinado à fermentação, menores as chances de contaminações indesejáveis e melhor a qualidade da fermentação. A limpeza do caldo é feita mediante filtração seguida de decantação. Pela decantação as partículas sólidas remanescentes no caldo filtrado e mais densas que o mesmo deslocam-se para o fundo do recipiente gerando o lodo do decantador (CARDOSO, 2006). Este subproduto, no presente trabalho foi empregado para fermentação e posterior produção de etanol combustível.

Durante a fermentação do caldo de canade-açúcar ocorrem várias contaminações do mosto fermentado com outros micro-organismos concorrentes das leveduras (SEBRAE, 2001b). Portanto, após término do ciclo fermentativo deve-se eliminar os contaminantes e revigorar as células através da lavagem do fermento com água potável (sem cloro), ácido e ar (CARDOSO, 2006). Esta água utilizada na lavagem do fermento contém algumas células de leveduras e substâncias nutritivas, sendo proposto neste trabalho, como fonte de matéria prima para produção de etanol.

A cachaça pode ser obtida por meio da destilação em alambique ou em coluna (RECHE et al., 2007). Quando a produção da cachaça é realizada em alambique, o destilado é separado em três frações diferentes, denominadas cabeça, cauda e coração (CARDOSO, 2006). Estas frações são separadas em função do grau alcoólico: cabeça (grau alcoólico de 70 a 50 $\% \mathrm{v} / \mathrm{v})$, coração ( 50 a $38 \% \mathrm{v} / \mathrm{v}$ ) e cauda (38 a $14 \% \mathrm{v} / \mathrm{v}$ ), sendo o coração a fração principal da aguardente (RODRIGUES FILHO \& OLIVEIRA, 1999).

Geralmente a fração cabeça, que representa $10 \%$ da destilação, é jogada fora por produtores mais rigorosos, pois compromete o sabor da cachaça e prejudica a saúde do consumidor quando incorporada à bebida (BOZA \& HORII, 1998).

O álcool combustível é um produto renovável, limpo e ecologicamente correto que contribui para a redução do efeito estufa, não afeta a camada de ozônio e diminui substancialmente a poluição do ar, minimizando os seus impactos na saúde pública (PETROBRÁS, 2007) quando comparado com os combustíveis fósseis.

Com a produção crescente de automóveis do tipo Total Flex e com o preço do petróleo em alta, o consumo de álcool combustível e a necessidade de reduzir as emissões de gases oriundos da queima de derivados do petróleo, estão apontando para uma mesma direção (SILVA, 2007).

Muitos produtores rurais não compreendem a importância de um bom planejamento antes de abrir um novo negócio e agem por impulso ao fazê-lo. Apenas planejando, não é garantia de sucesso imediato e de uma empresa sólida e lucrativa, contudo, a possibilidade de se cometer erros é reduzida enquanto a chance de se aproveitar as oportunidades é otimizada (FELIPPE JÚNIOR, 1995).

A análise da avaliação econômicofinanceira de um projeto é de grande importância gerencial, pois é um processo de avaliação da empresa, responsável por mostrar o seu desempenho diante do mercado (SEBRAE/RS, 1995). O desenvolvimento da análise permite a evidenciação de dados, que serão transformados em informações úteis ao bom gerenciamento da entidade, permitindo a detectação de problemas e consequente busca para resolução deles (NASCIMENO, 2006).

Este trabalho foi realizado com o intuito de mostrar como os produtores de cachaça podem ter uma produção versátil com a obtenção de um novo produto, o etanol, a partir de resíduos que até então para muitos seriam inúteis, sem agredir e comprometer o meio ambiente. Além disso, ainda poderão aumentar sua renda, diminuindo os custos.

\section{MATERIAL E MÉTODOS}

O presente trabalho foi realizado 
na fazenda Vargem Grande/Bananal, situada na Rodovia 342, km 04, no município de Salinas - MG, durante a safra 2008/2009.

Os equipamentos que foram utilizados no processo de produção do etanol foram:

Lodo do decantador;

Fração Cabeça;

Alambique de aço inox com capacidade de $1.000 \mathrm{~L}$;

Destilador de coluna contendo resfriador com serpentina e Coluna de retificação;

Duas dornas para fermentar o lodo, uma com capacidade de 800 L e outra de 1.000 L;

Dorna de armazenamento do destilado;

$>$ Dorna de aço inox para armazenamento do álcool com capacidade para $3.000 \mathrm{~L}$.

Alcoômetro.

A produção de etanol realizado no referente trabalho consistiu em um processo relativamente simples. Coletou-se o lodo do decantador e a água da lavagem do fermento em uma dorna, sendo preenchida durante o período de dois dias e fez-se a destilação dessa mistura em um alambique de aço inox armazenando o destilado em um recipiente de plástico. Juntou-se esse destilado com a fração cabeça e levou-se em seguida ao destilador de coluna para destilação final.

O processo de fabricação do etanol foi feito nas seguintes etapas:

1. O alambique de aço inox com volume médio de $1.000 \mathrm{~L}$ foi abastecido até $3 / 4$ do volume começando o aquecimento com vapor.
2. Foram colocadas neste alambique, a fração cabeça e o destilado que foi armazenado, sendo esses produtos aquecidos a uma temperatura de $90^{\circ} \mathrm{C}$.

3. Assim que o destilado começou a correr no resfriador foi fechada sua válvula de controle e aberta a válvula da coluna para que os vapores pudessem subir até atingir os pratos da coluna de destilação.

4. No momento em que foi aberta a válvula do vapor do destilado, sendo ligada a bomba de água, que tem a função de resfriar os vapores de álcool para que ele possa ser condensado.

5. O álcool já condensado foi colhido no bico de saída da coluna com um teor de $97^{\circ} \mathrm{GL}$ descendo até $90^{\circ} \mathrm{GL}$, sendo que, no momento em que ele chega a esse teor alcoólico a válvula de vapor do alambique foi fechada e a bomba de água desligada, cessando assim a destilação do álcool $\mathrm{r}$ terminando a primeira batelada.

6. Pelo fato da válvula de vapor do alambique estar fechada, todo o líquido que não foi transformado em álcool foi retornado da coluna para o alambique.

7. Finalizado o retorno do líquido para o alambique, novamente a válvula de vapor do alambique foi reaberta, repetindo assim todo o processo para a segunda batelada.

Normalmente são feitas três bateladas por cada destilação obtendo 260 a 280 litros de etanol a $94^{\circ} \mathrm{GL}$, sendo que cada batelada atinge de 25 a $30 \%$ do volume total do vinho (Figura 1). 


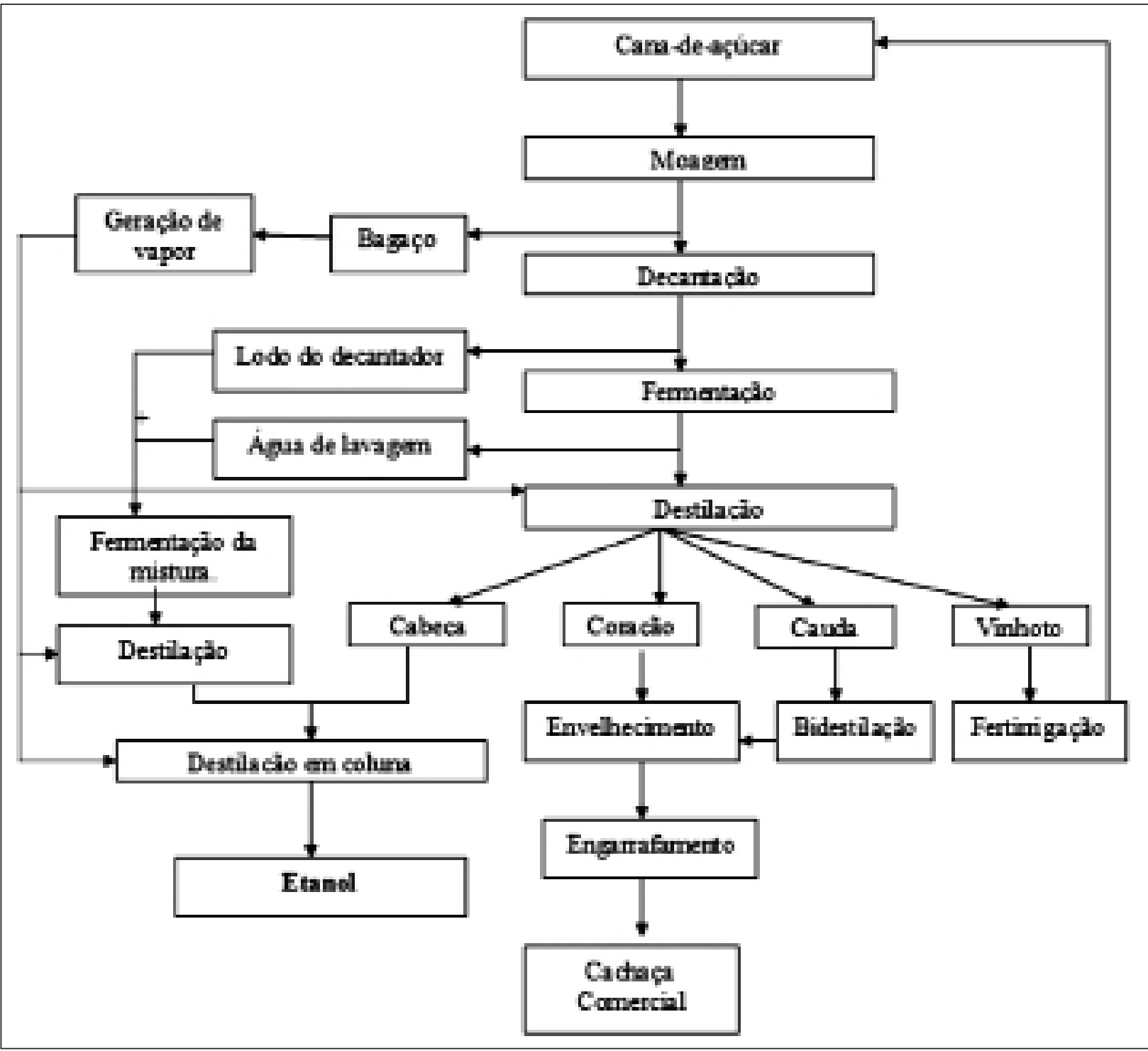

FIGURA 1 - Fluxograma do processo produtivo de etanol, utilizando-se subprodutos da indústria de cachaça na Fazenda Vargem Grande.

A avaliação econômico-financeira foi utilizada com orçamentos realizados através de pesquisas em casas comerciais no município de Salinas-MG, entrevistas com produtores rurais e consultas em sites especializados em vendas online.

\section{RESULTADOS E DISCUSSÃO}

Foram realizadas oito alambicadas por dia, sendo que em cada destilação foram retirados dois litros de fração cabeça, considerando que a safra teve duração de 180 dias, no final da safra obteve-se 2.880 litros da fração.

Coletou-se diariamente 300 litros de lodo do decantador (Figura 2) obtendo-se no final da safra 54.000 litros de lodo. 


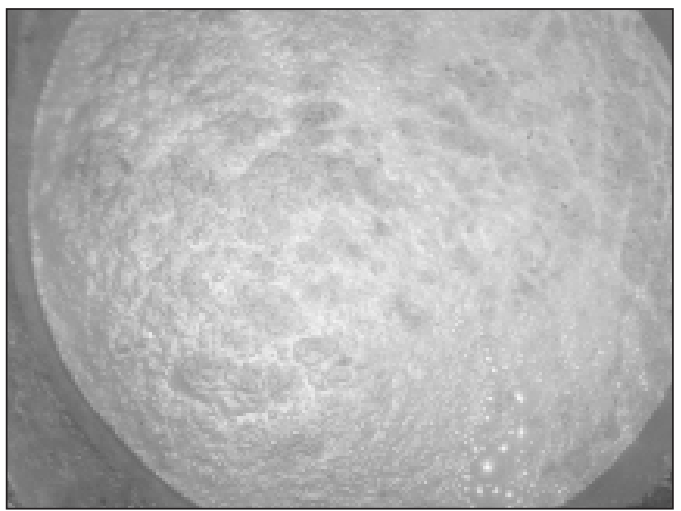

Figura 2 - Fotografia da mistura lodo de decantador e água de lavagem.

Foram coletados 540 litros de água de lavagem do fermento, sendo que foi feita essa lavagem uma vez por semana. No final da safra, com período de 24 semanas, obteve-se 12.960 litros de água de lavagem.

Durante toda a safra, armazenou-se em uma dorna de 800 litros uma mistura contendo 600 litros de lodo do decantador e 100 litros de água de lavagem onde sofreu fermentação. Após o processo fermentativo ter acabado, abasteceu-se o alambique de aço inox (Figura 3) com 700 litros de mistura fermentada, obtendo-se 120 litros, em média, do destilado com graduação alcoólica entre 40 e $42^{\circ} \mathrm{GL}$. No final da safra, a mistura de 54.000 litros de lodo do decantador e 12.960 litros de água de lavagem rendeu um volume de 11.478,85 litros de destilado.

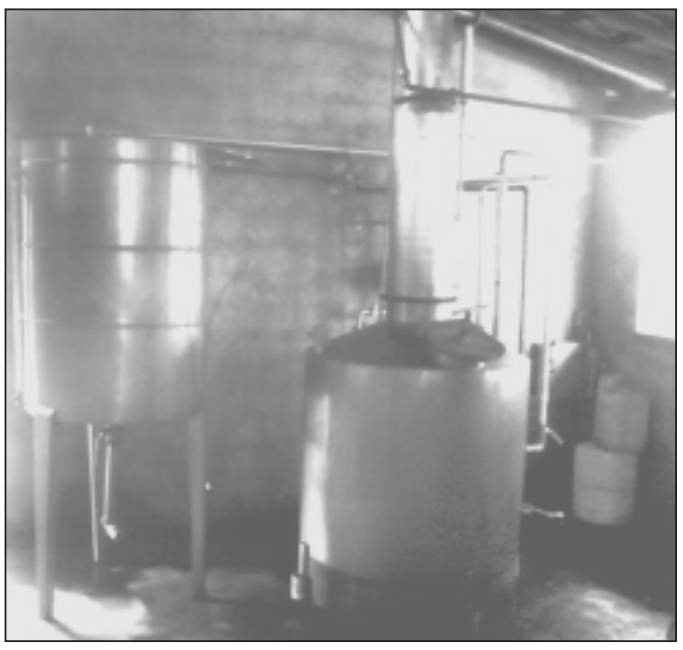

FIGURA 3 - Fotografia de um alambique de aço inox utilizado para destilação da mistura.

Em toda safra, foi misturado o volume total de $11.478,85$ litros de destilado da mistura lodo do decantador e água de lavagem, com 2.880 litros da fração cabeça, no qual a proporção média encontrada seria de 476,56 litros de etanol por 700 litros do volume do destilado (consulta ao produtor) sendo esperado, uma produção de 9.775,54 litros de etanol. Entretanto, no presente trabalho, foram gerados 8.000 litros de etanol com $95^{\circ} \mathrm{GL}$, com uma taxa de eficiência de $82 \%$ (Tabela 1) no processo de destilação em coluna (Figura 4).

TABELA 1. Eficiência produtiva da produção de etanol obtido de subprodutos da produção de cachaça na Fazenda Vargem Grande, Safra 2008/2009.

\begin{tabular}{ccc}
\hline Produto & & Quantidade \\
\hline Total de cachaça produzida. & & $80.000 \mathrm{~L}$ \\
Total de lodo do decantador. & $54.000 \mathrm{~L}$ \\
Total de água de lavagem. & $12.960 \mathrm{~L}$ \\
Total de fração cabeça. & $2.880 \mathrm{~L}$ \\
Total de etanol esperado. & $9.775,54 \mathrm{~L}$ \\
Total de etanol produzido. & $8.000 \mathrm{~L}$ \\
Eficiência produtiva. & $82 \%$ \\
\hline
\end{tabular}

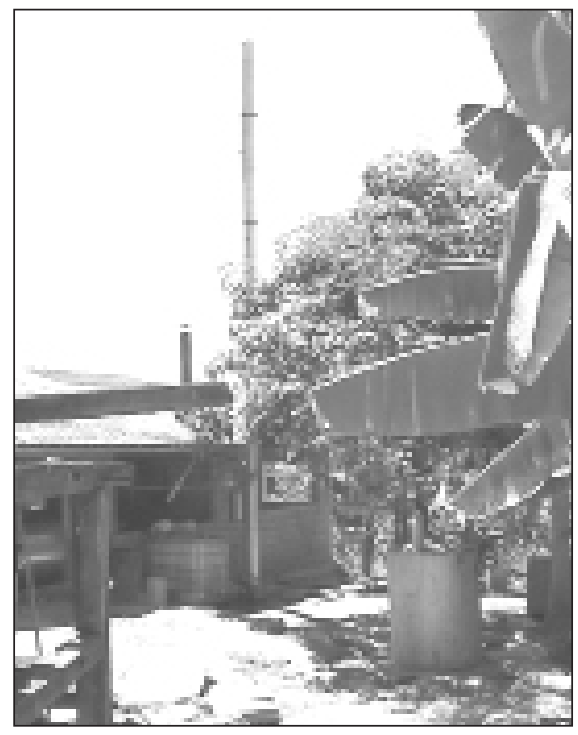

FIGURA 4 - Fotografia do destilador de coluna para produção de etanol. 
Considerando o preço do etanol combustível na capital Belo Horizonte, em média de $\mathrm{R} \$$ 1,899 por litro nos principais postos de gasolina (MERCADO MINEIRO, 2009), caso o produtor pudesse vender sua produção de etanol, esperavase que essa produção geraria uma receita bruta de R\$ $15.192,00$.

Custo variável é a soma dos fatores variáveis de produção (SEBRAE/RS, 1995). Custos que mudam de acordo com a produção ou a quantidade de trabalho, exemplos incluem o custo de materiais, suprimentos e salários da equipe de trabalho (SEBRAE, 2001a). Os custos variáveis foram estimados considerando que os insumos são subprodutos da produção de cachaça, sendo somados restos do caldo de cana-de-açúcar, despesas com água no processo de lavagem do fermento, lenha para aquecimento da fornalha e materiais diversos, como vasilhames, peneiras, mangueiras, alcoômetro, etc.

A margem de contribuição encontrada no presente trabalho foi de $\mathrm{R} \$ 14.427,00$ demonstrando viabilidade econômico-financeira, corroborando os resultados encontrados por MACHADO \& BORGES (2008), trabalhando com produção de etanol em grande escala. Margem de contribuição é o valor, ou percentual, que sobra das vendas, menos o custo direto variável e as despesas variáveis. A margem de contribuição representa o quanto a empresa tem para pagar as despesas fixas e gerar o lucro líquido (SEBRAE, 2001a).

Custos fixos é a soma de todos os fatores fixos de produção. Independente do nível de atividade da empresa, ou seja, produzindo-se ou vendendo-se em qualquer quantidade, os custos fixos existirão e serão os mesmos (SEBRAE/RS, 1995). Os custos fixos do presente trabalho foi de R\$ 5.850,00 sendo considerado o somatório do custo de um funcionário efetivo no período da safra, e o Pro-labore. Pro-labore é uma expressão latina que significa "pelo trabalho"; ou seja, é a remuneração do trabalho realizado por sócio, gerente ou profissional (SEBRAE, 2001a).

Lucro é o retorno positivo de um investimento feito por um indíviduo ou uma pessoa nos negócios. Lucro Operacional é a diferença positiva do lucro bruto e das despesas operacionais (FELIPPE JÚNIOR, 1995). No presente trabalho, o lucro operacional foi de $\mathrm{R} \$ 8.577,00$.

Ponto de equilíbrio, é a denominação dada ao estudo, nas empresas, principalmente na área da contabilidade, onde o total das receitas é igual ao total das despesas. Neste ponto o resultado, ou lucro final, é igual a zero (SEBRAE/RS, 1995). Neste trabalho, o ponto de equilíbrio foi de $\mathrm{R} \$ 6.160,20$ que é o resultado monetário necessário para pagamento das despesas. Considerando o resultado em litros de etanol, seria necessário a venda de pelo menos 3.243,92 litros de álcool combustível para custear sua produção.

Investimento é a aplicação de algum tipo de recurso (dinheiro ou títulos) com a expectativa de receber algum retorno futuro superior ao aplicado compensando, inclusive, a perda de uso desse recurso durante o período de aplicação. Num sentido amplo, o termo aplicase tanto à compra de máquinas, equipamentos e imóveis para a instalação de unidades produtivas (SEBRAE/RS, 1995). O resultado deste projeto, apresentou um investimento de R\$ 30.400,00; originado da aquisição de um destilador de coluna, alambique de aço inox e dornas para fermentação e armazenamento.

A lucratividade operacional indica o percentual de ganho obtido sobre as vendas realizadas (SEBRAE/RS, 1995). Nesta proposta, a lucratividade foi de $56,45 \%$, indicando uma bom retorno financeiro, semelhante dados obtidos por BENEDETTI et al., (2009) que obtiveram índices elevados utilizando celulose como matéria prima para produção de etanol.Rentabilidade indica o percentual de remuneração do capital investido na empresa (SEBRAE/RS, 1995). A taxa de rentabilidade do presente trabalho foi de $28,21 \%$, indicando uma boa avaliação econômico-financeira, com resultados correspondentes aos de BENEDETTI et al., (2009), que utilizaram celulose como matéria prima para produção de etanol. 
Prazo de retorno do investimento é o momento em que ocorre a recuperação de todo o capital investido pela empresa, ou seja, os lucros gerados cobrem o investimento realizado (SEBRAE/RS, 1995). O prazo de retorno do investimento no referido trabalho foi de 3,54 anos, indicando um bom retorno do capital empregado (QUADRO 1). Resultados estes que contrariam cenário pessimista de alguns autores que acusaram um longo prazo de retorno do investimento em usinas de etanol (JORNAL CANA, 2007).

QUADRO 1: Avaliação econômico-financeira da Produção de etanol a partir de subprodutos da produção de cachaça na fazenda Vargem Grande, safra 2008/2009.

\begin{tabular}{|c|c|}
\hline Análise econônico-financeira & Valor \\
\hline $\begin{array}{l}\text { Receita bruta (RB) } \\
\text { Venda de etanol combustível }\end{array}$ & $15.192,00$ \\
\hline Total & $15.192,00$ \\
\hline $\begin{array}{l}\text { Custos variáveis }(\mathrm{CV}) \\
\text { Insumos } \\
\text { Lenha para fornalha } \\
\text { Materiais diversos }\end{array}$ & $\begin{array}{l}465,00 \\
100,00 \\
200,00\end{array}$ \\
\hline Total & 765,00 \\
\hline $\begin{array}{l}\text { Margem de contribuição }(\mathrm{MC}) \\
\qquad \mathrm{MC}=\mathrm{RB}-\mathrm{CV}\end{array}$ & $14.427,00$ \\
\hline Total & $14.427,00$ \\
\hline $\begin{array}{l}\text { Custos fixos (CF) } \\
\text { Mão-de-obra } \\
\text { Pró-labore }\end{array}$ & $\begin{array}{l}2.850,00 \\
3.000,00\end{array}$ \\
\hline Total & $5.850,00$ \\
\hline $\begin{array}{l}\text { Lucro Operacional (LO) } \\
\qquad \mathrm{LO}=\mathrm{MC}-\mathrm{CF}\end{array}$ & $8.577,00$ \\
\hline Total & $8.577,00$ \\
\hline $\begin{array}{c}\text { Ponto de Equilíbrio (PE) } \\
\text { PE = CF/MC x RB } \\
\text { Ponto de Equilíbrio em litros de álcool (PE/1,899) }\end{array}$ & $\begin{array}{c}6.160,20 \\
3.243,92 \text { litros }\end{array}$ \\
\hline $\begin{array}{c}\text { Investimentos fixos (IF) } \\
\text { Destilador de coluna } \\
\text { Alambique de aço inox } \\
\text { Dornas para fermentação } \\
\text { Dornas para armazenamento }\end{array}$ & $\begin{array}{c}18.600,00 \\
6.000,00 \\
2.000,00 \\
3.800,00 \\
\end{array}$ \\
\hline Total & $30.400,00$ \\
\hline $\begin{array}{l}\text { Lucratividade Operacional (LOp) } \\
\qquad \mathrm{LOp}=\mathrm{LO} / \mathrm{RB} \times 100\end{array}$ & $56,45 \%$ \\
\hline $\begin{array}{c}\text { Rentabilidade Operacional (RO) } \\
\text { RO = LO / IF x } 100\end{array}$ & $28,21 \%$ \\
\hline $\begin{array}{c}\text { Prazo de retorno do investimento (PRI) } \\
\text { PRI = IF / LO }\end{array}$ & 3,54 anos \\
\hline
\end{tabular}




\section{CONCLUSÃO}

A produção de etanol em pequena escala traz vantagens e benefícios para o produtor de cachaça como geração de menores impactos ao meio ambiente, melhor aproveitamento de subprodutos, maior geração de renda e retorno financeiro para o produtor, além da produção de um biocombustível menos agressivo ao meio ambiente. Este é um trabalho incipiente e novos trabalhos de produção de etanol poderão ser realizados a partir daqui, inclusive aproveitando-se outros subprodutos como bagaço, pontas de cana-de-açúcar e outros.

\section{REFERÊNCIAS BIBLIOGRÁFICAS}

BENEDETTI， O. I. S.; CHAVES， R. Q.; MAGALHÃES, A. M.; BLOS, A. L. F.; SILVA, T. N. Análise preliminar da produção de etanol a partir de celulose: caminhos e desafios para a produção de álcool no Rio Grande do Sul. Engenharia Ambiental, v.6, n.2, p.272-284, 2009.

BOZA, Y.; HORII, J. Influência da destilação sobre a composição e a qualidade sensorial da aguardente de cana-de-açúcar. Ciência e Tecnologia de. Alimentos, v.18, n.4, p.391-396, 1998.

CARDOSO, Maria das Graças. Produção de Aguardente de Cana, 2a Edição. Lavras, Editora UFLA, 2006.

CHRISTOPH, N.; CHRISTOPH, C. B. Flavour of spirit drinks: raw materials, fermentation, distillation, and ageing. Flavours and fragrances chemistry, bioprocessing and sustainability, p.219-239, 2007.

FELIPPE JÚNIOR, B. Marketing para pequena empresa: o que é e para que serve. Brasília, Ed. SEBRAE, 1995.

MACHADO, R. L.; BORGES, M. B. Uma análise exploratória da cadeia produtiva do álcool etanol no Estado de Goiás. XXVIII ENCONTRO NACIONAL DE ENGENHARIA DE PRODUÇÃO. Rio de Janeiro, 2008.

MERCADO MINEIRO. Disponível em: http:// www.mercadomineiro.com.br/relatoriopostos. jsp Acesso em 12/11/2009, às $12 \mathrm{~h} 45 \mathrm{~min}$, 2009.

NASCIMENO, C. A. O. Cachaça: nicho de mercado ou alternativa estratégica? Revista Humanidades, Fortaleza, v. 21, n. 2, p. 188194, 2006.

PETROBRÁS. Disponível em: www. petrobras.com.br. Acessado no dia 15/10/2009 às $20 \mathrm{~h} 45 \mathrm{~min}, 2007$.

RODRIGUES FILHO, A.; OLIVEIRA, R. N. Tecnologia de produção de cana-de-açúcar e Cachaça de Minas de qualidade. Belo Horizonte, Ed. EMATER-MG, 1999.

RECHE, R. V.; LEITE-NETO, A. F.; DA SILVA, A. A.; GALINARO, C. A.; DE OSTI, R. Z.; FRANCO, D. W. J. Agric. Food Chem. v.55, p. 6603, 2007.

SEBRAE/RS. Estudo de viabilidade econômico-financeira. Porto Alegre, Ed. SEBRAE/RS, 1995.

SEBRAE. Sistemas integrados de gestão: meio ambiente, qualidade, saúde ocupacional, segurança e responsabilidade social: conceitos, definições e termos usuais. Brasília, Ed. SEBRAE, 2001a.

SEBRAE. Recomendações de controle ambiental para produção de cachaça. Vitória, Ed. SEBRAE, 2001b.

SILVA, J. S. Produção de Álcool Combustível na Fazenda e em Sistema Cooperativo. Viçosa, Ed. UFV, 2007. 